\begin{tabular}{llll} 
Abstract 129 Table 1 & & & \\
\hline Investigations & Case 1 & Case 2 & Case 3 \\
\hline Haemoglobin (g/L) & 70 & 67 & 70 \\
White cell counts (/L) & $1.5 \times 10^{6}$ & $2.5 \times 10^{6}$ & $3.5 \times 10^{6}$ \\
Lymphocyte count (/L) & $0.4 \times 10^{6}$ & $0.6 \times 10^{6}$ & $0.8 \times 10^{6}$ \\
Platelet count (/L) & $63 \times 10^{9}$ & $50 \times 10^{9}$ & $76 \times 10^{9}$ \\
Urine protein (mg/m²/hour) & 74 & & \\
C3 (Normal 50-150 mg/dL) & $<27$ & $<27$ & $<27$ \\
C4 (Normal 20-50 mg/dL) & 4 & 3 & 3 \\
ANA (immunofluorescence method) & $4+$ diffuse & $3+$ diffuse & $4+$ diffuse \\
Anti dsDNA (N:<60 IU/mL) & 707 & 583 & 1394 \\
Serum ferritin (ng/ml) & 3233 & 6767 & 1019 \\
Fasting triglyceride (mg/dl) & 442 & 504 & 328 \\
Fibrinogen (mg/dl) & 120 & 160 & \\
\hline
\end{tabular}

followed by mycophenolate. Her initial SLEDAI-2k was 25this decreased to 0 at 2 year follow-up.

Conclusions MAS can be the presenting manifestation of pediatric lupus and may contribute to disease severity and requires aggressive management

Funding Source(s): None

\section{JUVENILE SYSTEMIC LUPUS ERYTHEMATOSUS RELATED PANCREATITIS: AN UNCOMMON MANIFESTATION OF A COMMON DISEASE}

${ }^{1}$ Gummadi Anjani*, ${ }^{2}$ Ankita Singh, ${ }^{1}$ Rakesh Pilania, ${ }^{1}$ Nameirakpam Johnson, ${ }^{1}$ Pandiarajan Vignesh, ${ }^{2}$ Deepti Suri, ${ }^{3}$ Anju Gupta, ${ }^{2}$ Ankur Jindal, ${ }^{2}$ Surjit Singh. ${ }^{1}$ Dept. of Pediatrics, Allergy- Immunology Unit, Postgraduate Institute of Medical Education and Research; ${ }^{2}$ Postgraduate Institute of Medical Education and Research, Chandigarh, India; ${ }^{3}$ PGIMER Chandigarh

\subsection{6/lupus-2019-Ism.130}

Background Pancreatitis is a rare but potentially life-threatening complication of systemic lupus erythematosus(SLE).SLErelated pancreatitis can be a presenting manifestation of SLE or may occur during follow-up.

Methods We have reviewed the clinical records of 140 children with SLE between period of 1993-2018. We report 3 children with SLE who presented with acute pancreatitis.

Results Case1-12-year-girl presented with fever and alopecia. Examination revealed pedal oedema,periorbital puffiness, large joint arthritis.Investigations showed anemia,thrombocytopenia, elevated erythrocyte sedimentation rate(ESR), normal renal functions, microscopic hematuria,nephrotic range proteinuria, hypocomplementemia,antinuclear antibody (ANA) 4+,elevated anti double stranded DNA (anti-ds DNA),negative antiphospholipid antibodies (APLA) titre(table).Renal biopsy revealed Class 3 lupus nephritis and initiated on intravenous methylprednisolone.Two days later,she developed severe epigastric pain and vomiting. The pain increased in severity and physical examination revealed marked tenderness in the epigastrium. Serum amylase and lipase were elevated.Clinical possibilities included steroid induced pancreatitis and lupus pancreatitis.In view of severity of symptoms, intravenous methylprednisolone was continued following which she showed a dramatic improvement and normalisation of pancreatic enzymes. There has been no recurrence of pancreatitis over 3 years of followup period and remained well on low dose oral prednisolone (5 mg),mycophenolate-mofetil and hydroxychloroquine.
Abstract 130 Table 1 Investigation Table

\begin{tabular}{|c|c|c|c|}
\hline Investigation & Case 1 & Case 2 & Case 3 \\
\hline Haemoglobin ( $g / L)$ & $92 \mathrm{~g} / \mathrm{L}$ & $96 \mathrm{~g} / \mathrm{L}$ & $80 \mathrm{~g} / \mathrm{L}$ \\
\hline White cell counts & $7.7 \times 10^{6} / \mathrm{L}$ & $7.8 \times 10^{6} / \mathrm{L}$ & $7.5 \times 10^{6} / \mathrm{L}$ \\
\hline \multirow[t]{2}{*}{ Lymphocyte count } & $2.15 \times 10^{6} /$ & $1.9 \times 10^{6} / \mathrm{L}$ & $1.95 \times 10^{6} /$ \\
\hline & $\mathrm{L}$ & & $\mathrm{L}$ \\
\hline \multirow[t]{2}{*}{ Platelets } & $130 \times 10^{9} /$ & $150 \times 10^{9} / \mathrm{L}$ & $420 \times 10^{9} /$ \\
\hline & $\mathrm{L}$ & & $\mathrm{L}$ \\
\hline Urine routine & $10-12$ & Few RBC, & No RBC, \\
\hline \multirow[t]{4}{*}{ Urine protein ( $\mathrm{mg} / \mathrm{m}^{2} /$ hour) } & RBC, 3 & 3+albumin & 3 \\
\hline & +albumin & $82 \mathrm{mg} / \mathrm{m}^{2} / \mathrm{hr}$ & +albumin \\
\hline & & & $40 \mathrm{mg} /$ \\
\hline & & & $\mathrm{m}^{2} / \mathrm{hr}$ \\
\hline C3 (Normal 50-150 mg/dL) & $23.4 \mathrm{mg} /$ & $129 \mathrm{mg} / \mathrm{dL}$ & $34 \mathrm{mg} / \mathrm{dl}$ \\
\hline \multirow[t]{3}{*}{ C4 (Normal $20-50 \mathrm{mg} / \mathrm{dL}$ ) } & $\mathrm{dl}$ & $37 \mathrm{mg} / \mathrm{dL}$ & $10 \mathrm{mg} / \mathrm{dl}$ \\
\hline & $2.98 \mathrm{mg} /$ & & \\
\hline & $\mathrm{dl}$ & & \\
\hline ANA & 4+diffuse & $3+$ & 3+diffuse \\
\hline Anti dsDNA (N:<60 IU/mL) & 890 & $<60$ & 123 \\
\hline Antiphospholipid antibodies: a) & Negative & Negative & Positive \\
\hline Lupus anticoagulant b) & Negative & Negative & Negative \\
\hline Anticardiolipin antibody (IgG and & Negative & Negative & Negative \\
\hline \multirow{2}{*}{\multicolumn{4}{|c|}{$\begin{array}{l}\operatorname{IgM}) \text { c) Anti B2 Glycoprotein -1 } \\
\text { antibody (IgG and IgM) }\end{array}$}} \\
\hline & & & \\
\hline Skin biopsy & Not done & Positivity of lupus band test & Lupus \\
\hline & & with high positive $\operatorname{lgG}, \lg A$, & band test \\
\hline & & $\operatorname{lgM}$ and $\mathrm{C} 3$ in dermal & -positive \\
\hline & & vessels & \\
\hline \multirow[t]{4}{*}{ Renal biopsy } & Class 3 & $\lg G, \lg A, \lg M$ positivity in & Class 4 \\
\hline & lupus & the mesangium as well as & lupus \\
\hline & nephritis & capillary loops and C3 in & nephritis \\
\hline & & small sized blood vessels & \\
\hline Serum amylase $(<100 \mathrm{U} / \mathrm{L})$ & $238 \mathrm{U} / \mathrm{L}$ & $400 \mathrm{U} / \mathrm{L}$ & $290 \mathrm{U} / \mathrm{L}$ \\
\hline Serum lipase $(<60 \mathrm{U} / \mathrm{L})$ & $231 \mathrm{U} / \mathrm{L}$ & Not done & Not done \\
\hline
\end{tabular}

Case2-A-6-year-old presented with pain abdomen and vomiting.Physical examination showed epigastric tenderness.Investigations showed anemia,thrombocytopenia,elevated amylase levels(table).Computerised tomography(CT) abdomen revealed acute necrotising pancreatitis.A follow-up ultrasound abdomen revealed a pancreatic pseudocyst.He had a second episode of acute pancreatitis along with anasarca after 3 months which improved with conservative management.Investigation showed anemia,nephrotic range proteinuria and microscopic haematuria(table).ANA was positive with normal complement levels and negative anti-dsDNA titres(table).Lupus band test on skin biopsy was positive. Renal biopsy showed mesangioproliferativeglomerulonephritis with full house pattern.Following the initiation of steroids, he improved and there has been no recurrence of pancreatitis over the next 4 years.

Case 3-9 year-girl presented with generalised rash,alopecia for 5 months.She also had pain abdomen for last 2 months. Investigations showed elevated amylase,ultrasound abdomen revealed acute pancreatitis. She had undergone a laparotomy elsewhere.Examination showed generalised pigmented rash,alopecia, periorbital puffiness, hard palatal ulcer,surgical scar on the abdomen.Investigations showed anemia, normal platelet count,elevated ESR, normal renal functions,nephrotic range proteinuria,elevated serum amylase.Ultrasound and CT abdomen revealed a pancreatic pseudocyst.A clinical possibility of SLE 
with acute pancreatitis and lupus nephritis was considered.Further investigations were suggestive of lupus(table). Workup for APLA revealed positive lupus anticoagulant.Her skin biopsy was consistent with lupus and renal biopsy revealed class 4 lupus nephritis.She was initiated on oral prednisolone and was given pulses of intravenous cyclophosphamide.There has been no recurrence of pancreatitis over 12 years follow-up.

Conclusions Pancreatitis can at times, be the presentation of childhood lupus and requires prompt and aggressive management.

Funding Source(s): None

\section{STIMULATION OF MONONUCLEAR CELLS THROUGH TOLL-LIKE RECEPTOR 9 INDUCES RELEASE OF MICROVESICLES EXPRESSING DNA AND GALECTIN 3- BINDING PROTEIN IN AN INTERFERON-DEPENDENT MANNER}

${ }^{1}$ Soren Jacobsen*, ${ }^{1}$ Niclas Stefan Rasmussen, ${ }^{1}$ Christoffer Tandrup Nielsen, ${ }^{2}$ Claus Henrik Nielsen. 'Lupus and Vasculitis Clinic, Rheumatology, Copenhagen University Hospital, Rigshospitalet; ${ }^{2}$ Institute of Inflammation Research, Rheumatology, Copenhagen University Hospital, Rigshospitalet

10.1136/lupus-2019-Ism.131
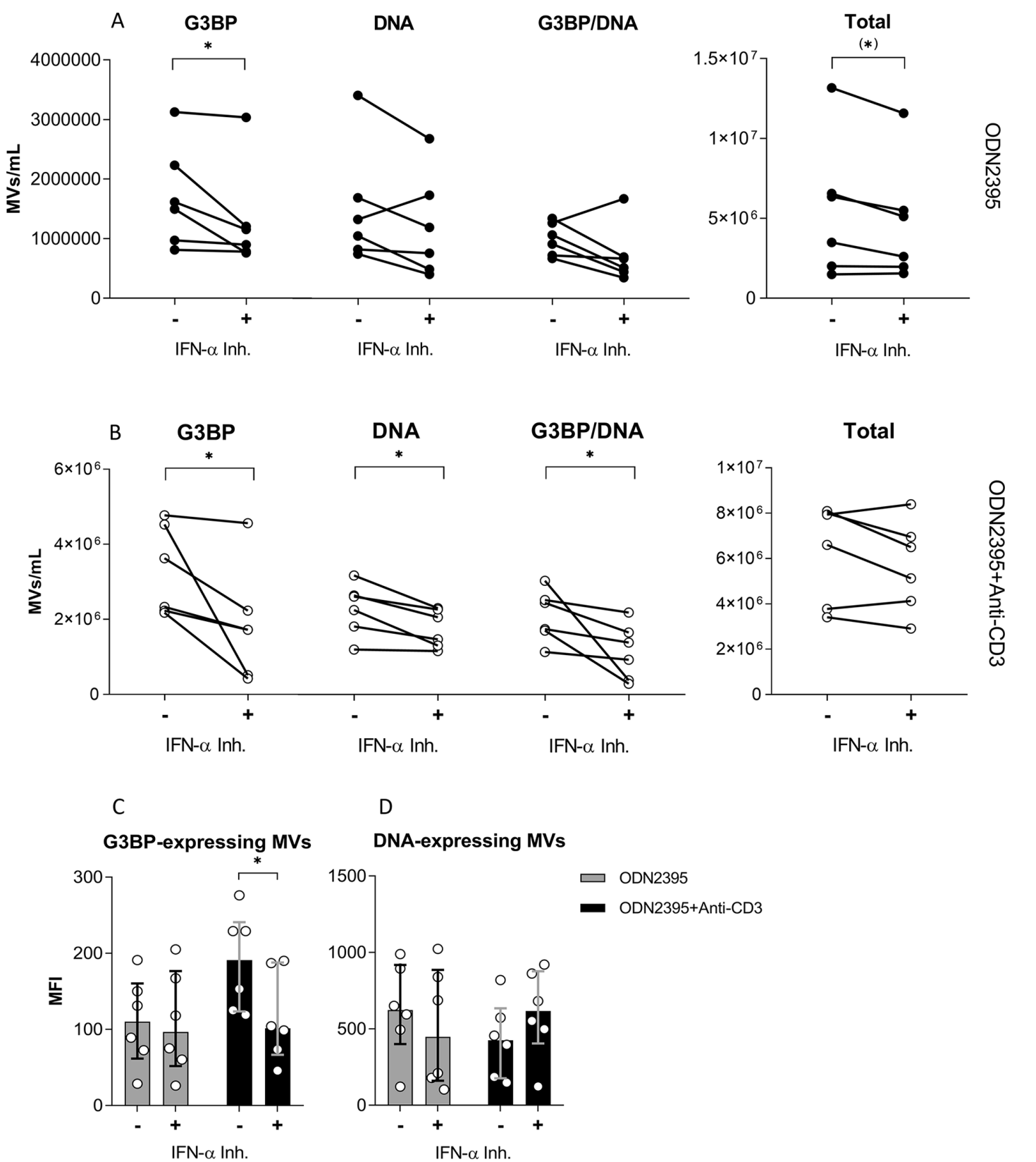

D

DNA-expressing MVs

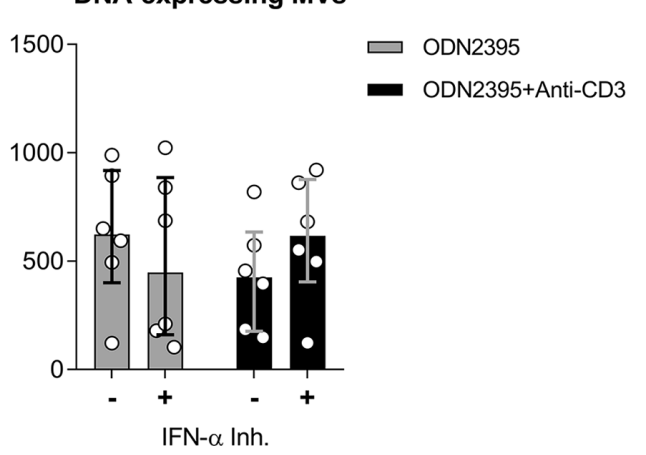

Abstract 131 Figure 1 PBMCs from healthy donors $(n=6)$ were incubated for 24 hours with the TLR9-agonist ODN2395, alone (-) or in combination with the IFN- inhibitor IFN alpha-IFNAR-IN-1 hydrochloride (+). MVs released into the culture supernatants were subsequently isolated by differential centrifugation, quantified and characterized with respect to expression of G3BP and DNA by flow cytometry. (A) Concentration in the culture supernatant of G3BP-expressing MVs, DNA-expressing MVs, and G3BP/DNA double-positive MVs. (B) Corresponding concentration of MVs expressing these markers when co-stimulating T-cells with anti-CD3 antibody. (C) The G3BP-derived median fluorescence intensity (MFI) of the G3BPexpressing MV population and (D) the DNA-derived MFI of the DNA-expressing MV population released from the ODN2395-treated PBMCs in presence (black columns) or absence (gray columns) of anti-CD3 antibody (OKT3). Columns and error bars represent median values and interquartile range. $\left({ }^{*}\right) \mathrm{P}<0.1 .{ }^{*} \mathrm{P}<0.05$. 